\title{
TEXTURE EVOLUTION OF EXPERIMENTAL SILICON STEEL GRADES. PART I: HOT ROLLING
}

\author{
J. A. Sandoval Robles $^{1}$, A. Salas Zamarripa ${ }^{1}$, M. P. Guerrero Mata ${ }^{1}$, and J. Cabrera ${ }^{2}$
}

${ }^{1}$ Universidad Autónoma de Nuevo León, Facultad de Ingeniería Mecánica y Eléctrica, Ave. Universidad S/N, Cd. Universitaria, San Nicolás de los Garza, Nuevo León, C.P. 66450, México.

2 Universitat Politècnica de Catalunya, Departament de Ciència dels Materials I Enginyeria Metal-lúrgica. Av. Diagonal 647, Barcelona, 08028, España.

${ }^{*}$ Corresponding author:

Facultad de Ingeniería Mecánica y Eléctrica, Universidad Autónoma de Nuevo León, Av. Universidad S/N, Ciudad Universitaria, C.P. 66451, Apartado Postal 076 Suc. "F" San Nicolás de los Garza, N.L., México Telephone: +52 (81)13404020 Ext. 1619

Fax: $+52(81) 83320904$

E-mail address: jsandoval.uan|@yahoo.com 


\section{Abstract}

The metallurgical understanding of the deformation processes during the fabrication of non-oriented electrical steels plays a key role in improving their final properties. Texture control and optimization in these steels is critical for the enhancement of magnetic properties. The aim of this work was to study the texture evolution of six non-oriented experimental silicon steels grades during hot rolling. These steels were low carbon steels with a silicon content varied from 0.5 to $3.0 \mathrm{wt} \%$. The first rolling program was performed in the austenitic $(\mathrm{y}-\mathrm{Fe})$ region for the steel with a $0.5 \mathrm{wt} \%$ of silicon content, while the $1.0 \mathrm{wt} \%$ silicon steel was rolled in two-phase $(\alpha-\gamma)$. Steels with higher silicon content were rolled in the ferritic ( $\alpha-\mathrm{Fe})$ region. The second rolling program was performed in the $\alpha$-Fe region. Samples of each stage were obtained and analyzed by means of Electron Backscatter Diffraction (EBSD). Findings suggested that the texture was random and heterogeneous in all samples after $60 \%$ of rolling reduction due to the low deformation applied. After the second rolling program, localized deformation and substructure grains near to surface were found in all samples. Goss $\{110\}<001>$ component was found in the 0.5 and $1.0 \mathrm{wt} \%$ silicon steels. It is due to the thermomechanical conditions and the hot band microstructure achieved during the first program. Moreover, $\alpha<110>/ / R D$ and $y<111>/ / N D$ fiber components presented a considerable increment as the silicon content increases. Future research in this direction will be related to the texture evolution during the cold-work rolling program.

Keywords: Texture; Electron Backscattering Diffraction; Non-oriented silicon steels. 


\section{Introduction}

Non-oriented silicon steels are the most used magnetic soft material due to their low core loss and high permeability. Their use is focused in electrical machinery such as motors, generators, etc. The proper alloying, thecontrol of the grain size and texture are mechanisms to obtain the desired magnetic properties [1-4]. Physical-metallurgical methodologies, such as the control of hot band microstructure and crystallographic texture have been used to improve high magnetizing ability at a constant level of core loss. Moreover, it is well known the effect of the hot band microstructure in the crystallographic texture, and consequently, in the final product. Optimization of the hot rolling practice holds the key to a cheaper and easiest way to influence the hot band microstructure [2-5].

In terms of texture, Goss component $(\{110\}<001>)$ is important due to the easiest magnetization direction $<001>$ which is parallel to the sheet surface, whereas the $\gamma$-fibre texture $(\{111\}<u v w>)$ needs to be avoided [6-8]. However, during the hot rolling of nonoriented silicon steels, the desired texture components are the cube $\{001\}<011>$ and rotated cube $\{001\}<110>$ because they are the second best substitute for the ideal texture $[9,10]$.

The aim of this work was to study the texture evolution of six experimental silicon steel grades after hot rolling schedule using Electron Back-Scattering Diffraction (EBSD), in order to relate the final texture to the thermomechanical conditions and alloying content used during this research. 


\section{Experimental Procedure}

The experimental silicon steel grades used in this work were hot rolled to a final thickness of $2 \mathrm{~mm}$ following the schedule shown in Figure 1. Reheating was performed at $1150^{\circ} \mathrm{C}$ for $1 \mathrm{~h}$ before each program. According to the silicon equivalent content equation $\left(\mathrm{Si}_{\mathrm{eq}}=\% \mathrm{Si}+2[\% \mathrm{Al}]-0,50[\% \mathrm{Mn}]+2.92[\% \mathrm{P}]\right)$ and the $\mathrm{Fe}-\mathrm{Si}$ phase diagram [11] (Figure 2), the first rolling program consisted in a total reduction of $60 \%$. It was performed in the $\mathrm{y}$-Fe region for the steel with a $0.5 \mathrm{wt} \%$ of silicon content, while the 1 wt\% silicon steel was rolled at intercritical temperature. Steels with higher silicon content were rolled in the $\alpha-F e$ region. The second rolling program was carried out in the $a-F e$ region. In the Table 1 is detailed the chemical composition and the sample identification of these steels.

Texture of all samples was measured by means of EBSD technique using a DigiView IV camera connected to a JEOL JSM-6510LV scanning electron microscope (SEM). A $1 \mathrm{~mm}^{2}$ area was scanned in all samples in the normal and transversal (near surface) direction. The step size employed was selected based on the average grain size. Grain size analysis was performed using the average grain size given by the OIM data analysis software. The grain size measurement is based on the misorientation angle between grains. Texture was analyzed using Orientation Distribution Functions (ODF's). In order to quantify the texture of each sample, a comparison of the intensity of the components was performed.

\section{Results and discussion}




\subsection{Grain size analysis}

It is well established that larger ferrite grain size in hot band is one of the most important factors for the final magnetic performance of non-oriented electrical steels [1-5, 7-10]. Moreover, grain size prior to the final cold rolling stage is important for the development of the Goss component in these steels [5, 9]. Figure 3 shows the average grain size obtained during the first rolling program by means of the OIM analysis. The grain size growth as the silicon content increases, however, the largest grains were found in the S25 sample, while a major quantity of smaller grains was found in the S30 specimen. This behavior continued during the second rolling program (as seen in Figure 4). However, the microstructure in the bulk section of all samples consisted of equiaxied grains, while highly deformed and substructured grains were found in the regions near to the rolling surface(as seen in Figure 5). The presence of smaller grains indicates the beginning of recrystallization.

\subsection{Texture analysis}

Figure 6 shows the ODF's in $\varphi_{2}=45^{\circ}$ for all samples. Texture was random in all samples after the first rolling program. It was due to the deformation applied (60\% reduction) which was not enough to modify the crystal orientation [6]. Table 2 summarized the intensities of the principal components found in the samples. Samples S05, S10 and S15 showed $<110>$ oriented components. While $<111>$ oriented components were presented from the samples S05 to the S20. 
An increment on the cube and rotated cube texture components ( $\alpha$ fiber) was observed after the second rolling program (see Figure 5 and Table 3). An increase on the intensity of the $y$ fiber was also found. These two fibers were expected to present an increment after a 70\% thickness reduction [8, 9]. Samples S25 and S30 showed the highest intensities of components within these fibers. Goss component was found only in the S05 and S10. As mentioned above, the first rolling program of these two steels was performed in $\gamma$-region and intercritical temperature, which indicates that rolling in these zones facilitate to achieve the desired texture components [2]. Moreover, higher texture intensities were found in the near surface, rather than in the bulk section, due to the higher deformation produced by shear stress between the rolling rod and the sample (see Table 4).

\section{Conclusions}

The results of the experiment to investigate the effect of the texture evolution of six nonoriented experimental silicon steels grades during hot rolling obtained the following conclusions:

- The larger grain size was obtained in the S25 (2.5 wt\% silicon content) after the two rolling programs, which indicates an improvement in the magnetic properties. The second rolling program produced equiaxed grains in the bulk section. Recrystallization starts until the second rolling program, in which deformed and substructured grains were found near to the rolling surface. 
- The first rolling program produces a random texture in all samples. Evidence of Cube and rotated Goss texture components was found in the samples rolled in the $\gamma$-region and $\alpha+\gamma$ region.

- Texture improvement was found in all samples after the second rolling program. Rolling in g-region and $\mathrm{a}+\mathrm{g}$ during the first program presents a positive effect in the formation of Goss component in the samples S05 and S10. The intensity of cube and rotated cube components was improved as the silicon content increases.

- As far as the global results from this work, the best grain size and texture were found in the sample S25. Further work to be published will be focused in the texture evolution during cold-work rolling program, and the results will be related with the final hot band microstructure achieved in the hot rolling program.

\section{Acknowledgements}

The authors gratefully acknowledge the financial support of FONDO DE COOPERACIÓN INTERNACIONAL (FONCICYT) project ACERLECT No. 93325 for their financial support.

\section{References}

1. Verbeken, K., Schneider, J., Verstraete, J., Hermann, H., and Houbaert, Y. Effect of hot and cold rolling on grain size and texture in Fe-2.4wt\%Si strips. IEEE Trans on Magn. 44 (2008) 3820-3823.

2. Fischer, O. and Schneider, J. Influence of deformation process on the improvement of non-oriented electrical steel. J. Magn. Magn. Mater. 254-255 (2003) 302-306. 
3. Huñady, J., Černık, M., Hilinski, E.J., Predmerský, M., and Magurová, A. Influence of chemistry and hot rolling conditions on high permeability non-grain oriented silicon steel. J. Magn. Magn. Mater. 304 (2006) e620-e623

4. Sidor, J., Verbeken, K., Gomez, E., Schneider, J., Rodriguez, P. and Kesten, L. Through process texture evolution and magnetic properties of high Si non-oriented electrical steels. Mat Char 71 (2012) 49-57.

5. Kestens, L. and Jacobs, S. Texture control during the manufacturing of nonoriented electrical steels. Texture, Stress and Microstructure. Volume 2008 (2008), Article ID $173083,1-9$.

6. Humphreys, F.J. Recrystallization and related annealing phenomena, Elsevier, UK, 2004.

7. Houbaert, Y., Ros-Yáñez, T., Monsalve. A. and Barros, J. Texture evolution in experimental grades of high-silicon electrical steel. Physica B 384 (2006) 310-312.

8. Kumano, T., Kubota, T., and Takahashi, N. Texture of primary recrystallization on nonoriented electrical steel sheet with phase transformation. JMEPEG 4 (1995) 401 412.

9. Chaudhury, A., Khatirkar, R., Viswanathan, N., Singal, V., Ingle, A., Joshi, S., and Samajdar, I. Low silicon non-grain-oriented electrical steel: Linking magnetic properties with metallurgical factors. J. Magn. Magn. Mater. 313 (2007) 21-28.

10. PremKumar, R., Samajdar, I., Viswanathan, N.N., Singal, V. and Seshadri, V. Relative effect(s) of texture and grain size on magnetic properties in a low silicon non-grain oriented electrical steel. J. Magn. Magn. Mater. 264 (2003) 75-85.

11. Kubaschewski, O. Iron-Binary phase diagrams, Springer-Verlag, New York, 1982. 
30 옹 Reduction

$Z^{a t} 973{ }^{\circ} \mathrm{C}$

$30 \%$ Reduction

K at $960^{\circ} \mathrm{C}$

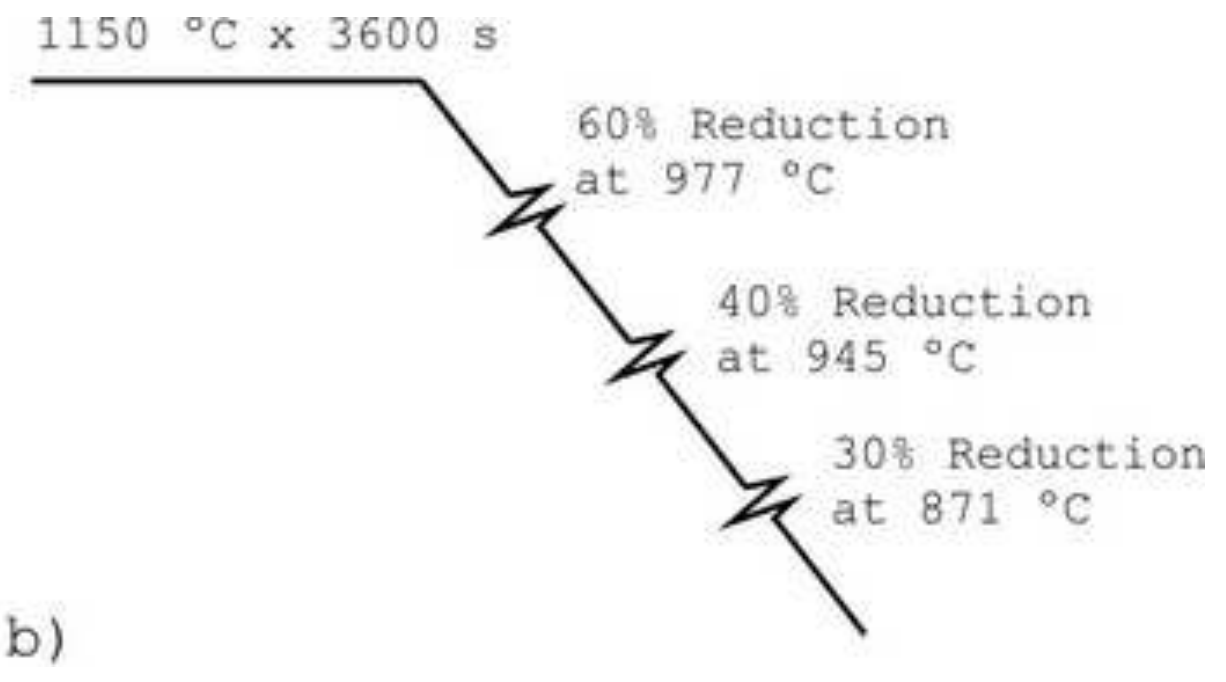

b) 


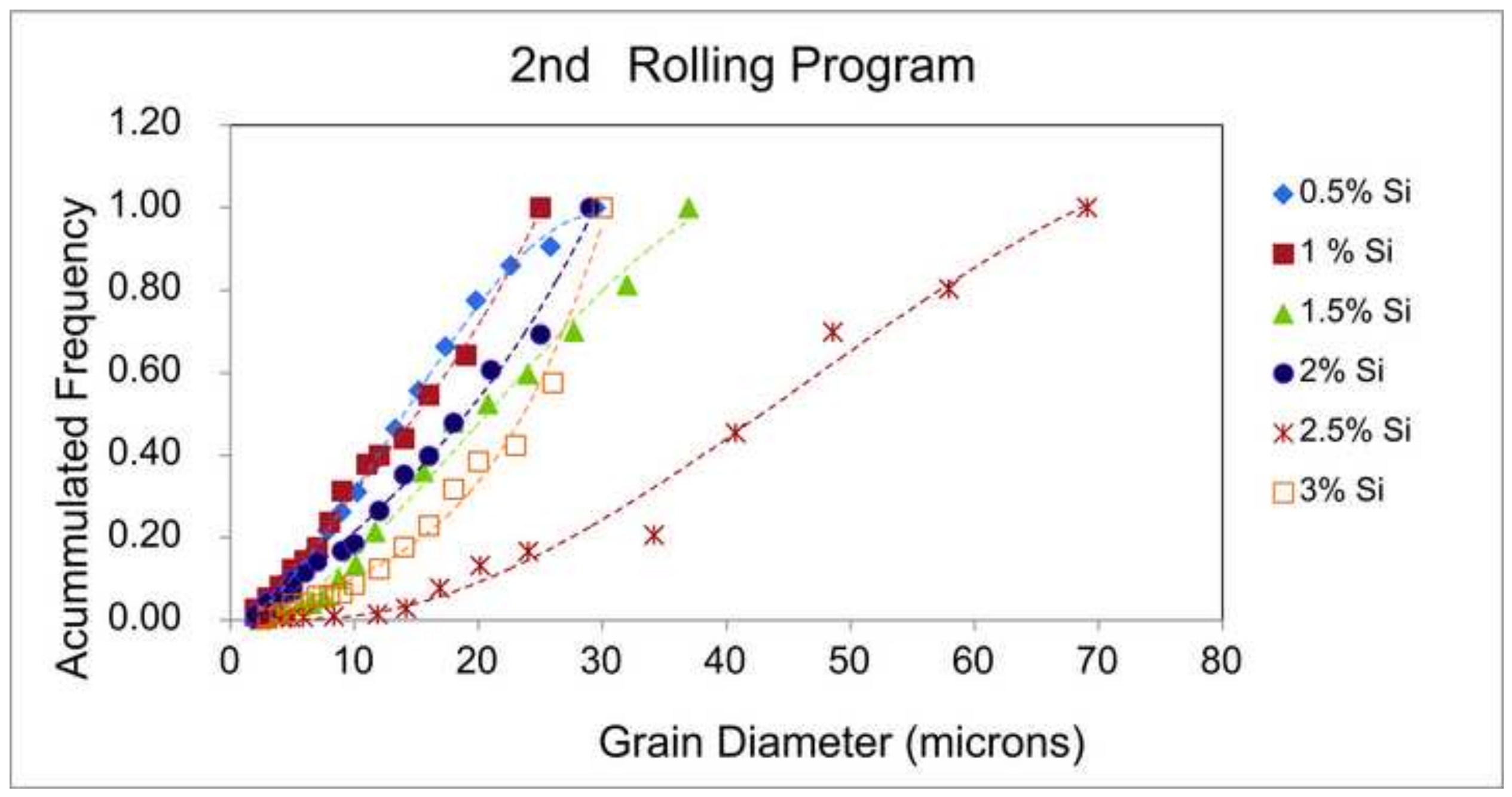




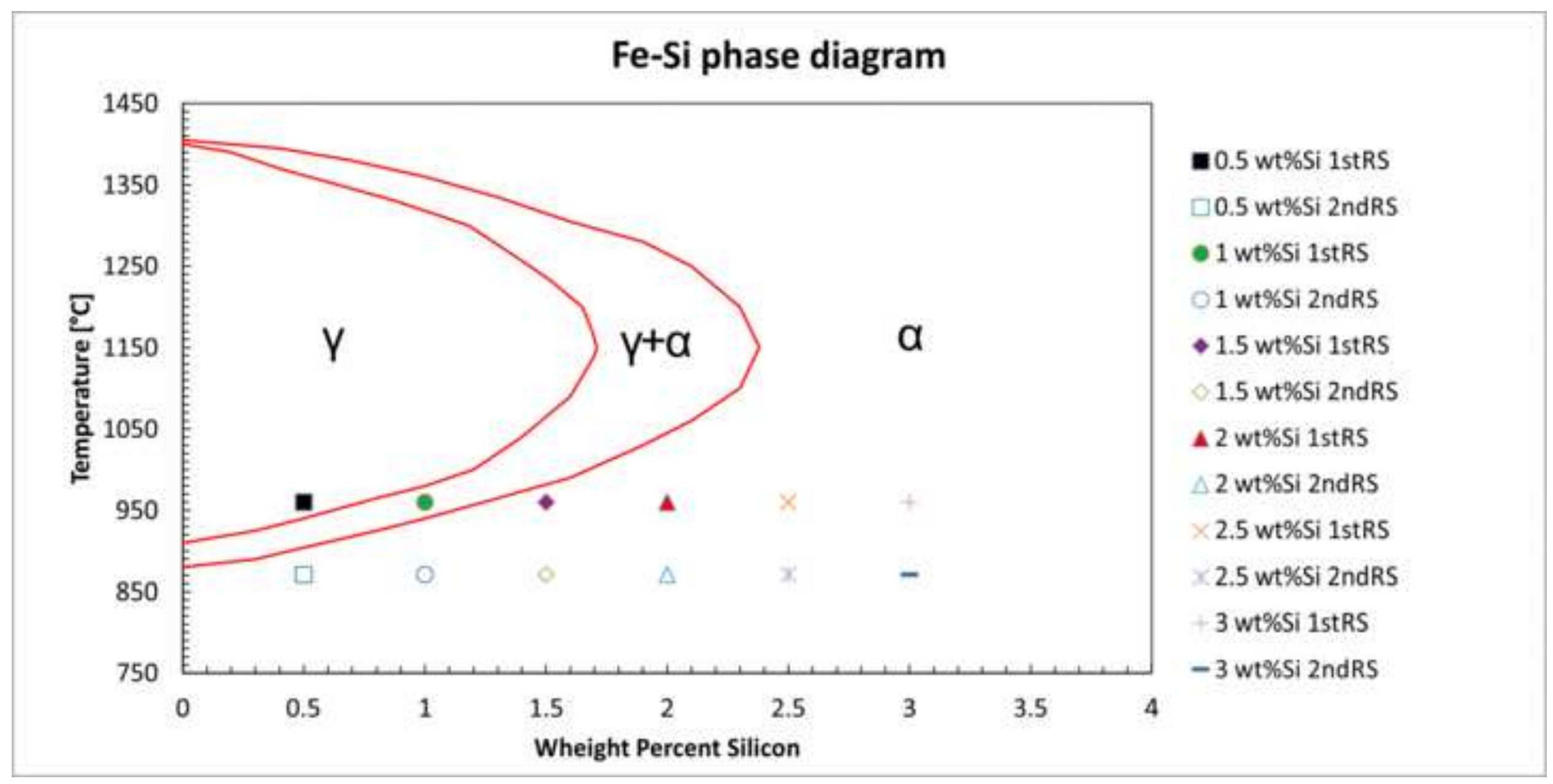




\section{1st Rolling Program}

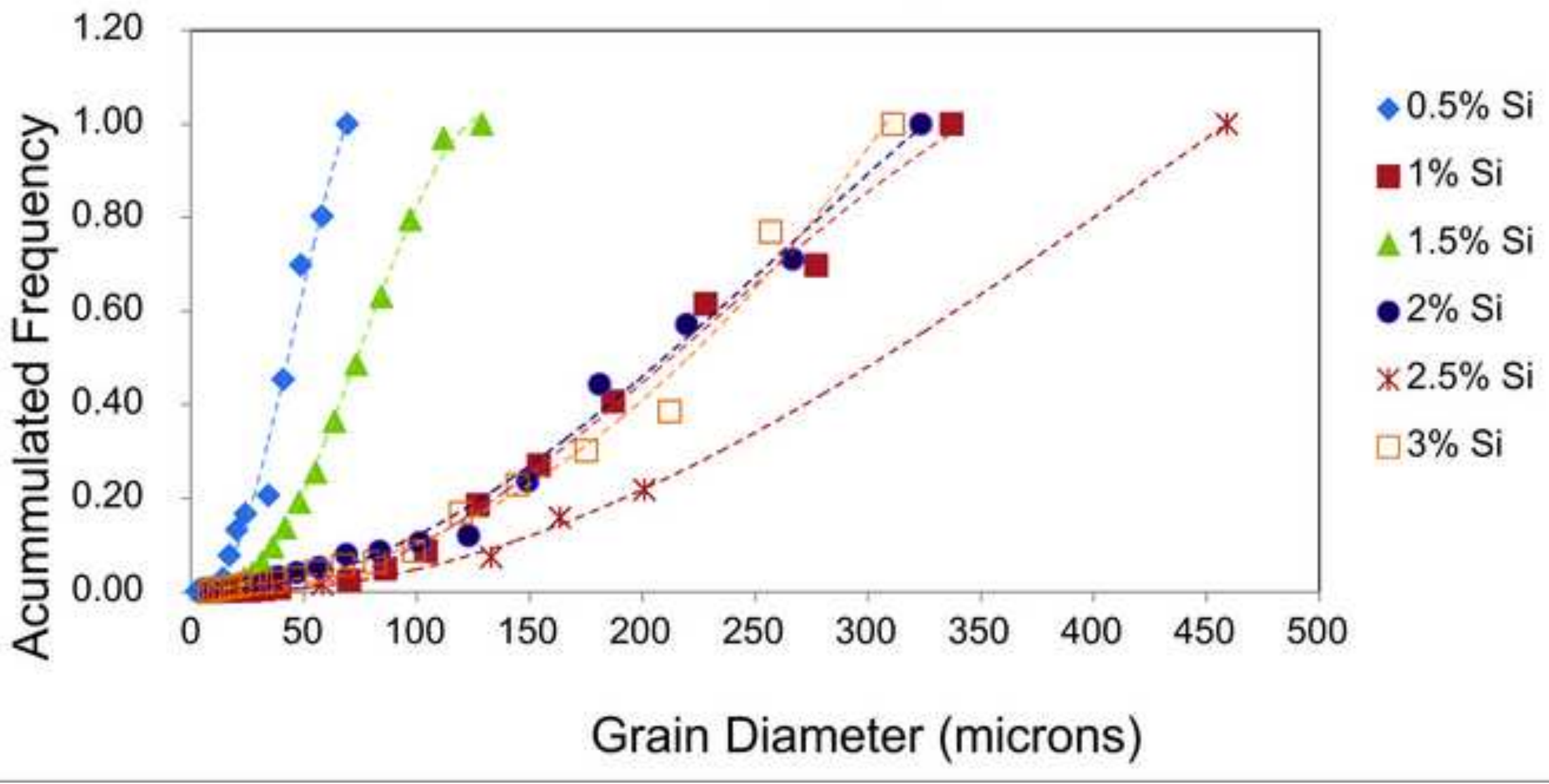


Click here to download high resolution image

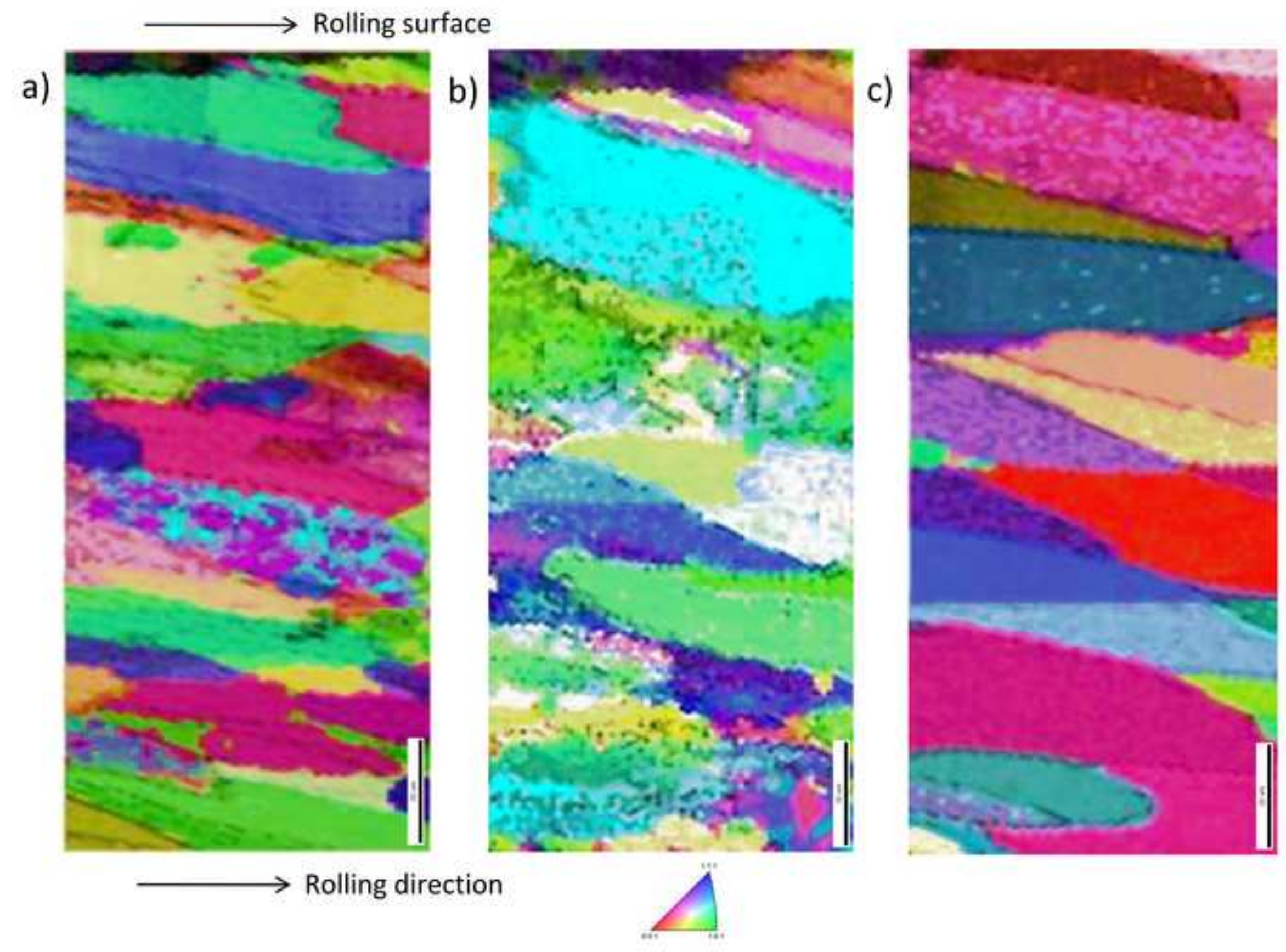

b) c)

Rolling direction

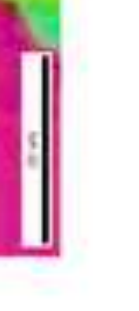

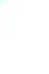


Click here to download high resolution image

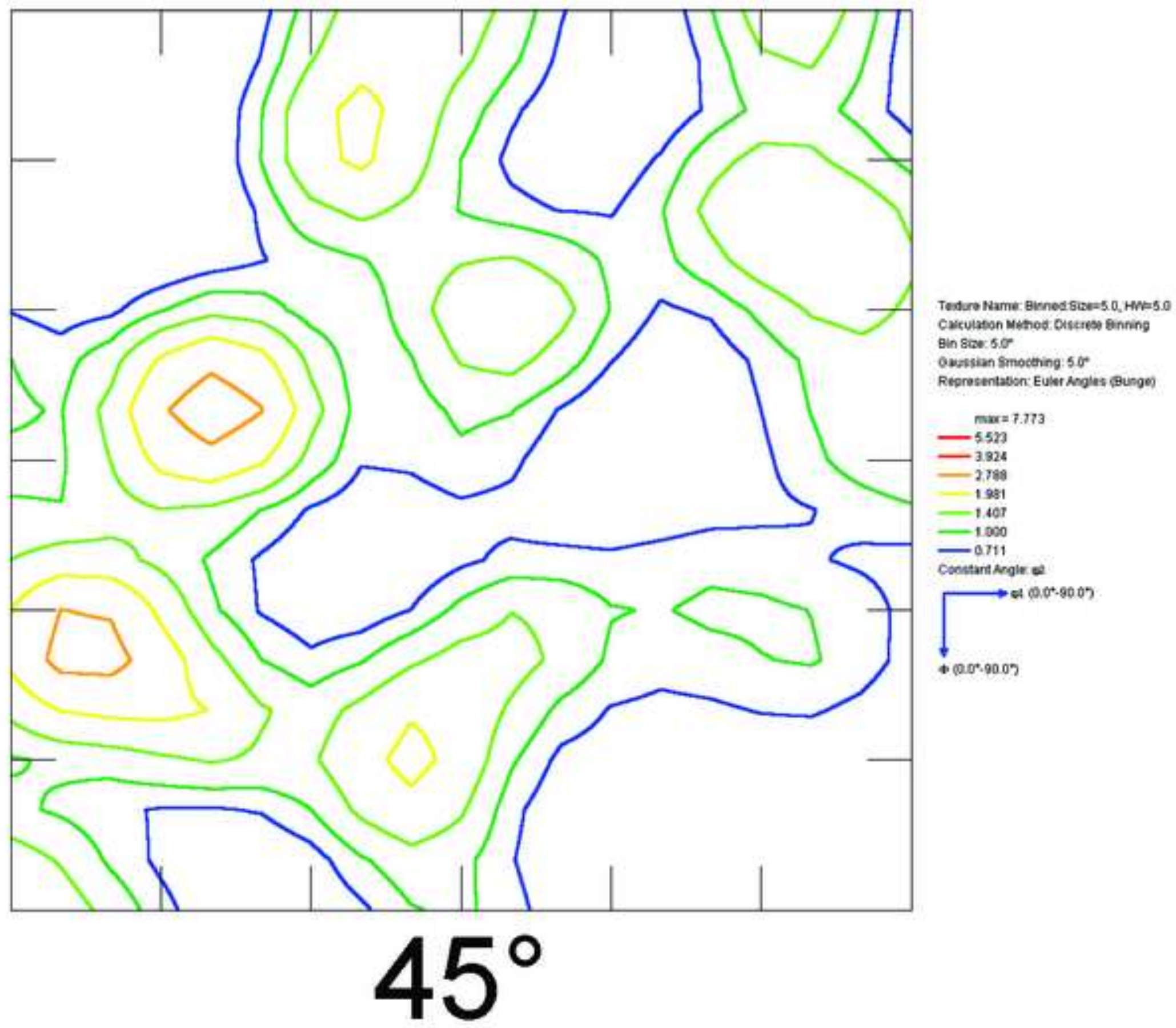


Click here to download high resolution image

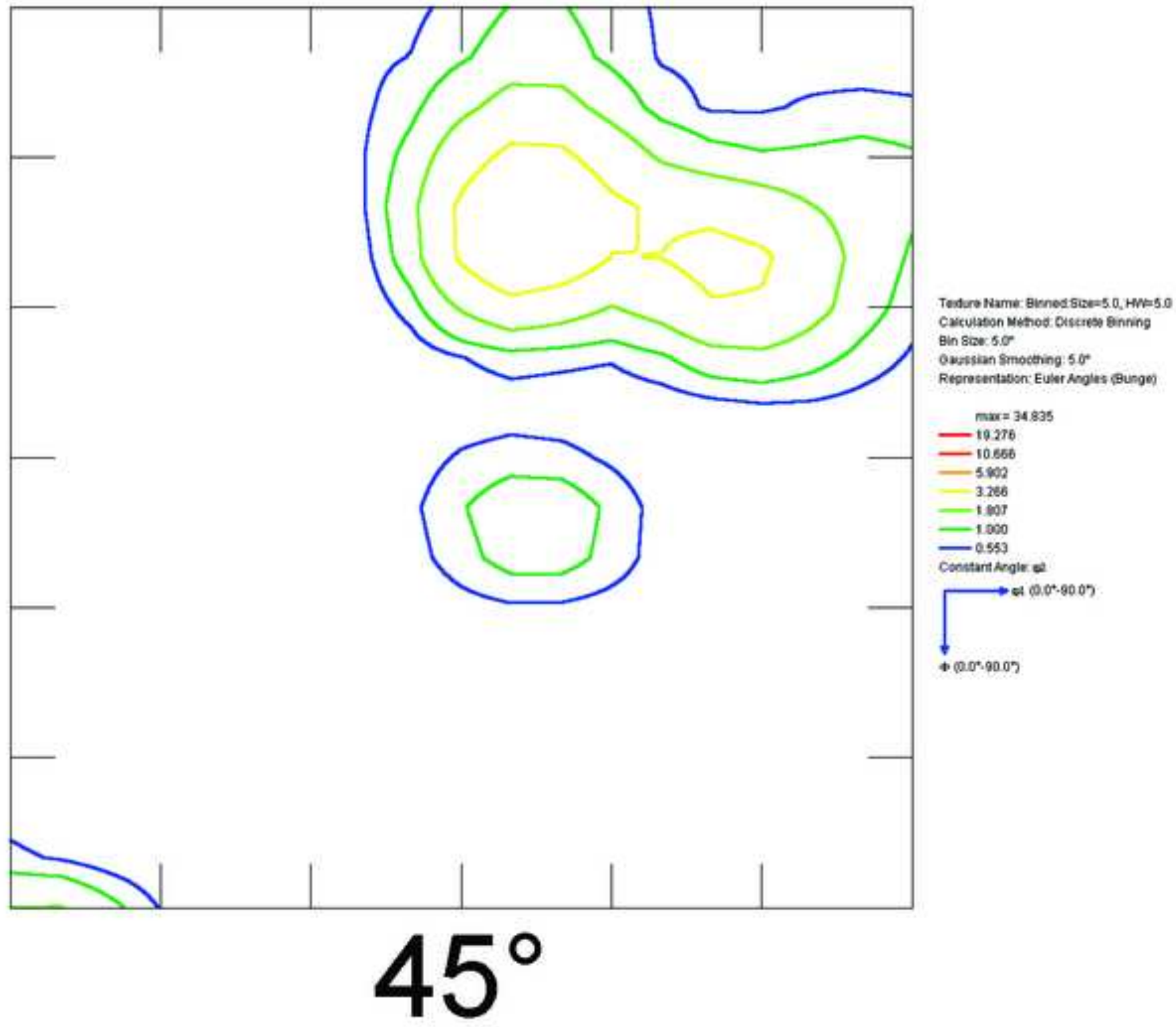


Click here to download high resolution image

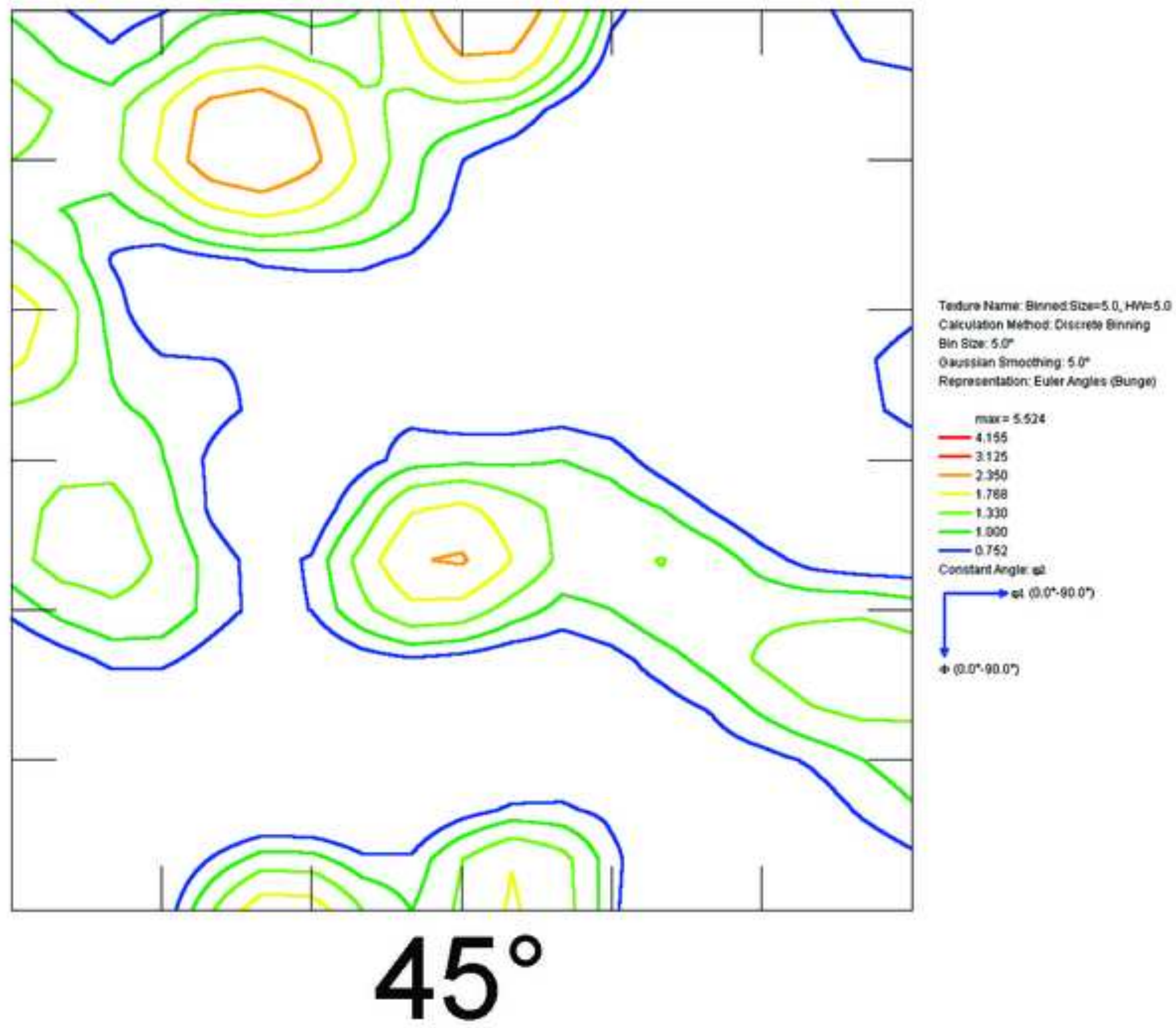


Click here to download high resolution image

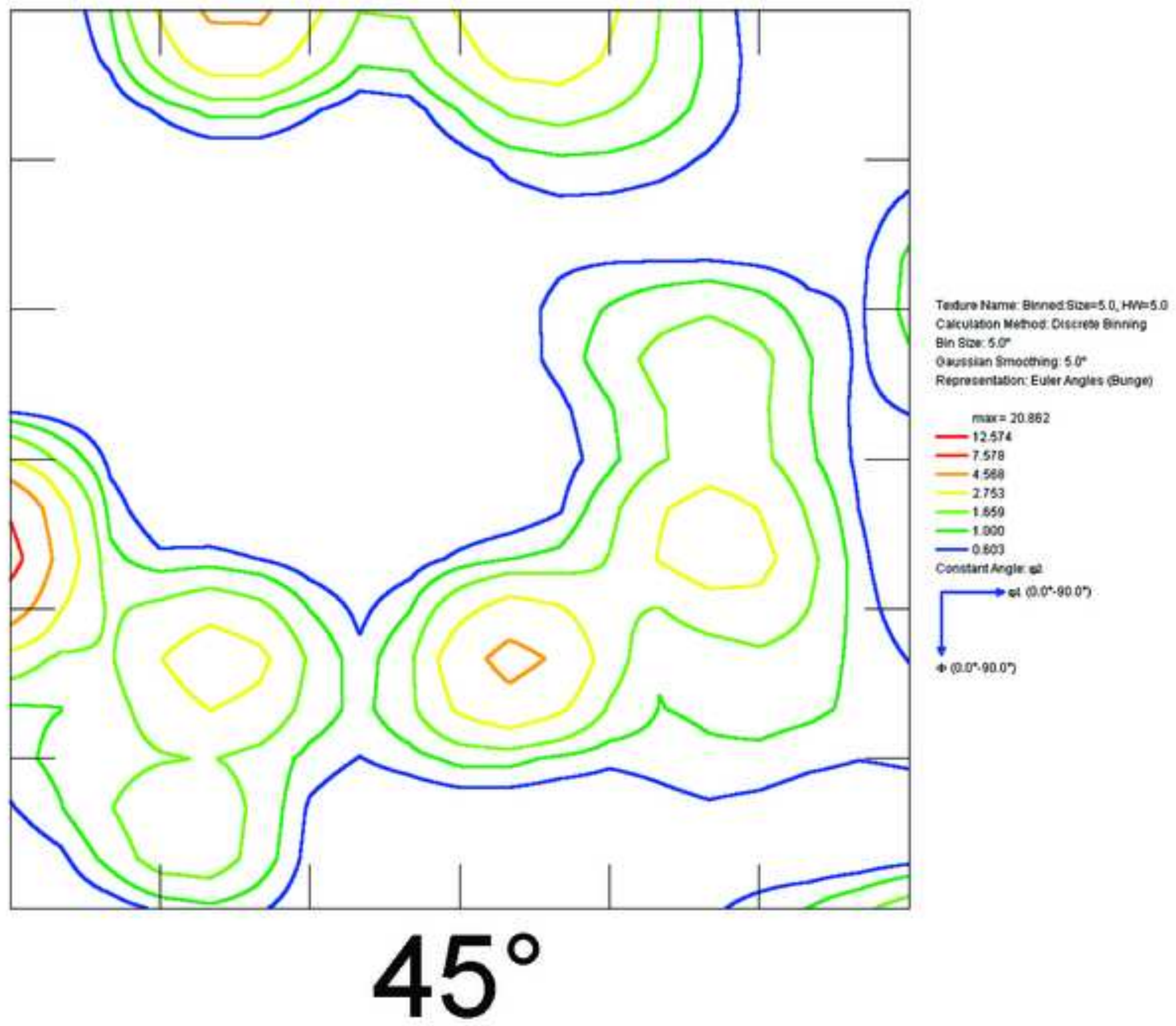




\section{gure}

Click here to download high resolution image

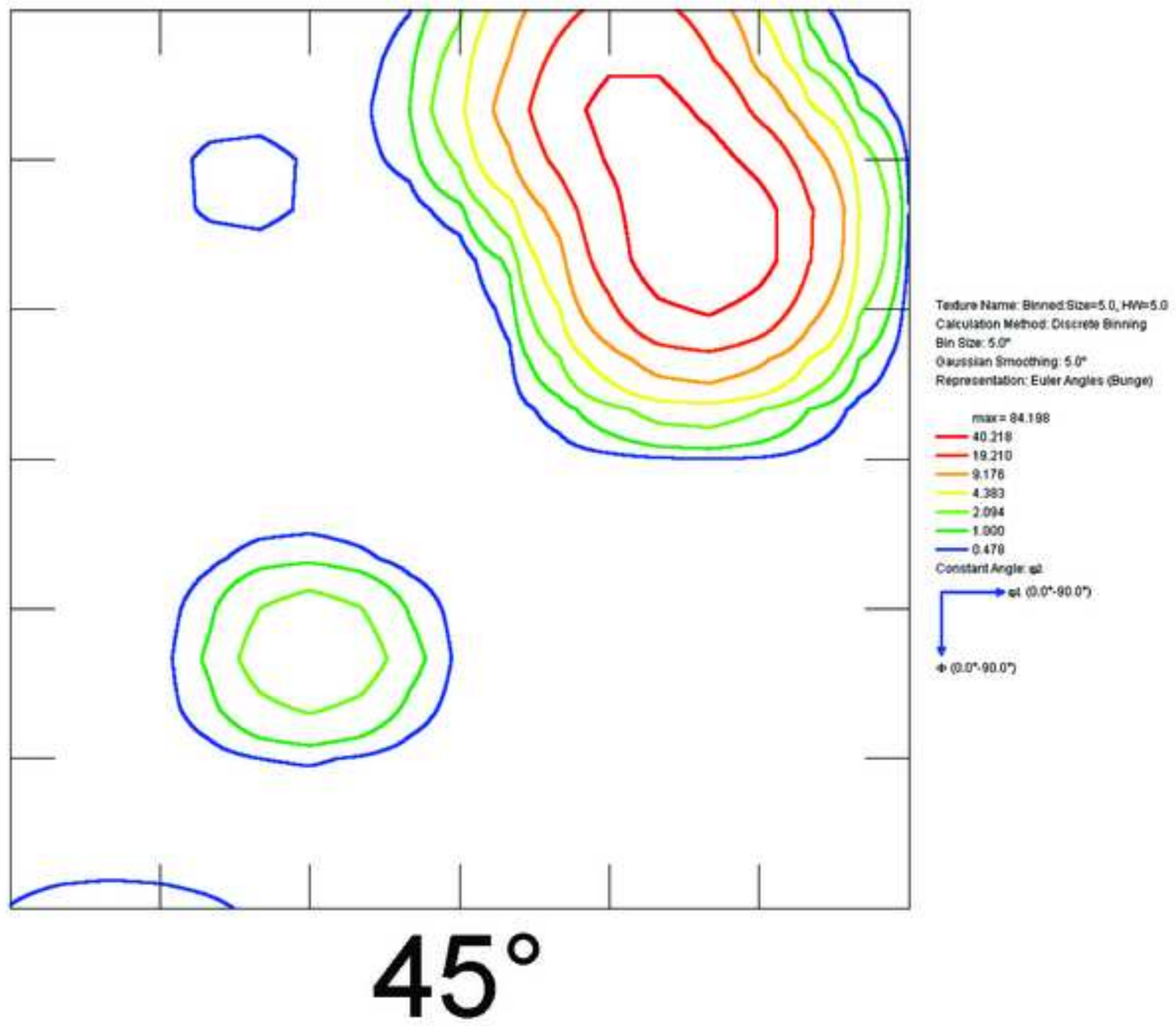


Click here to download high resolution image

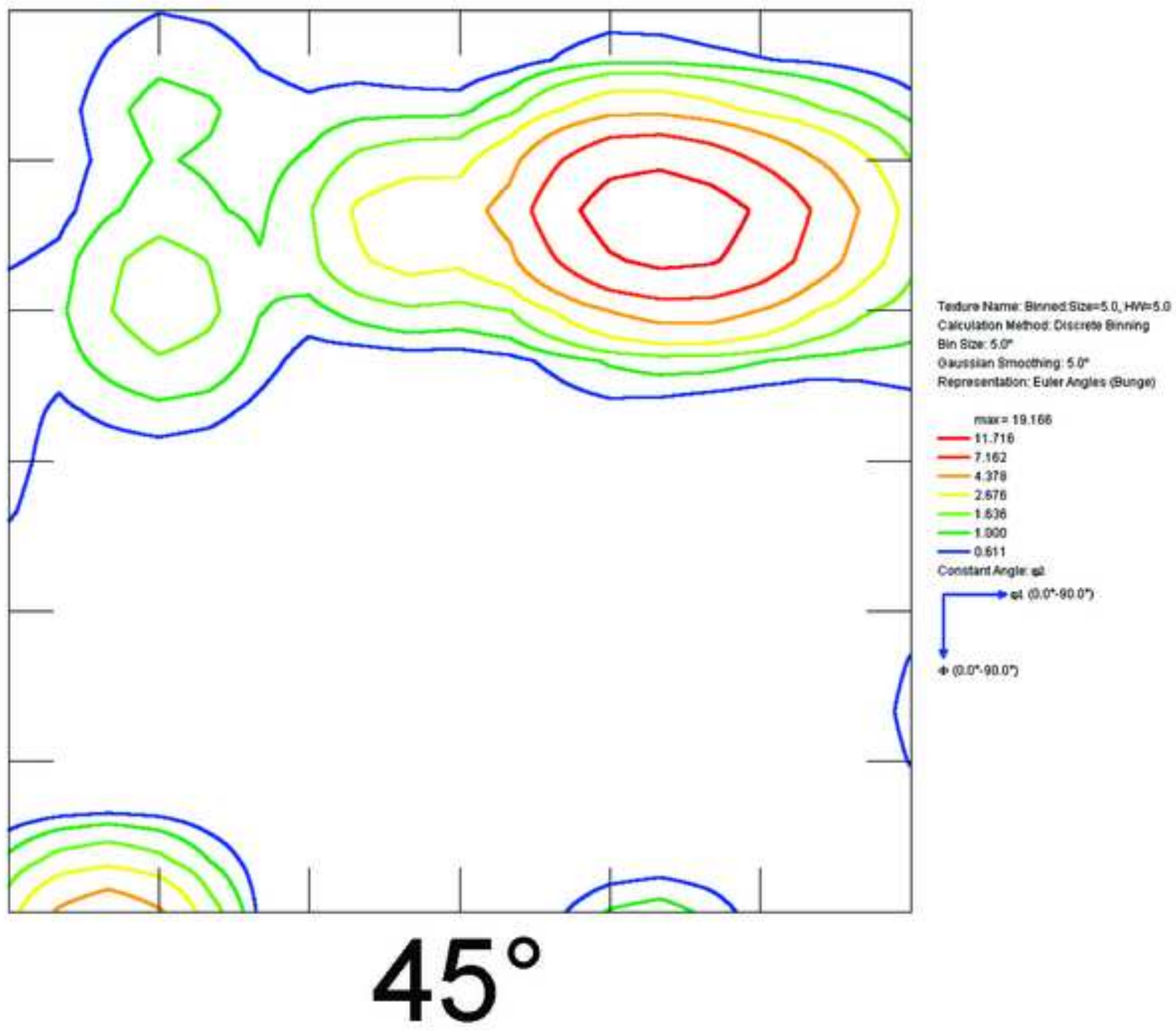


Click here to download high resolution image

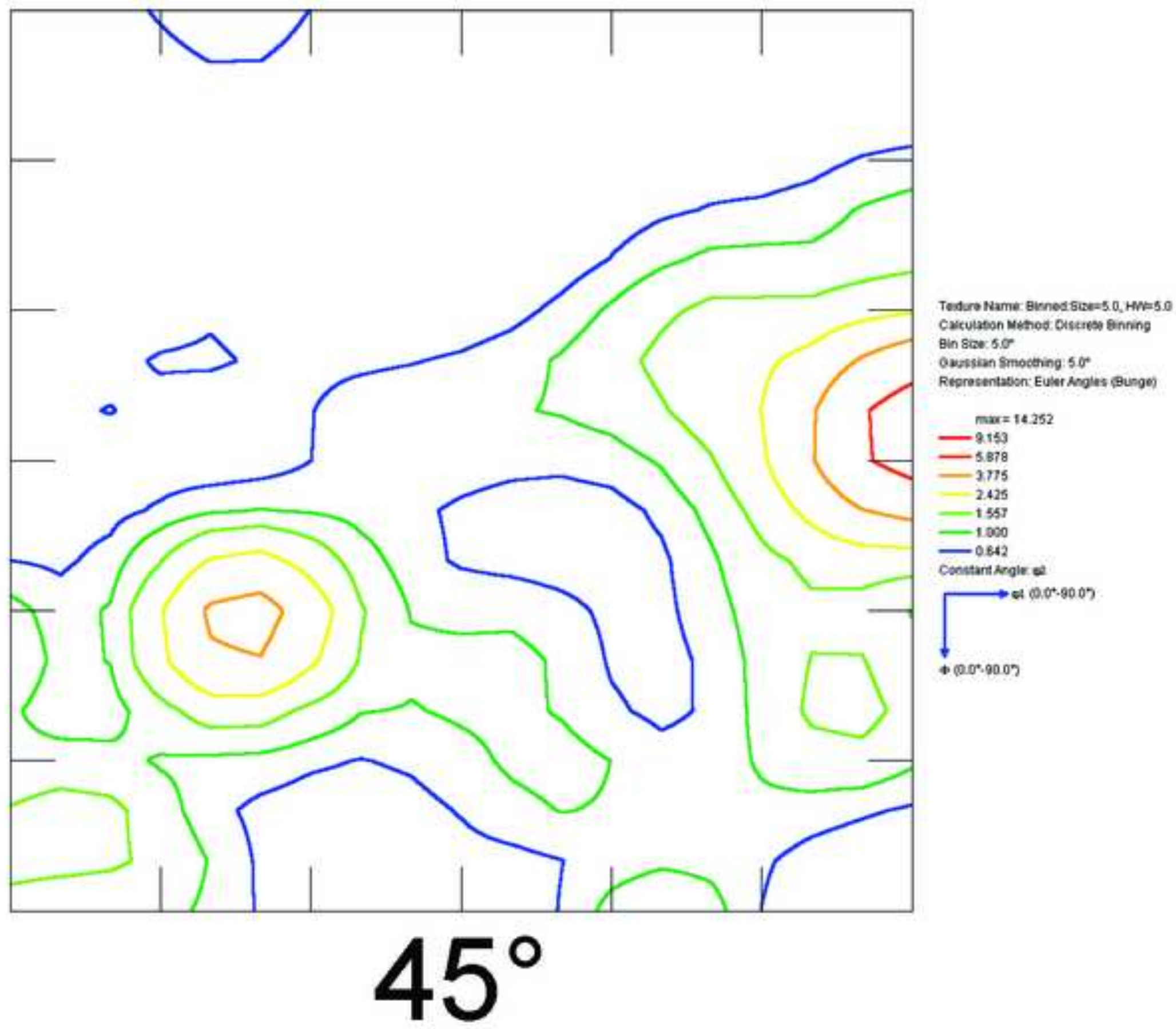


Click here to download high resolution image

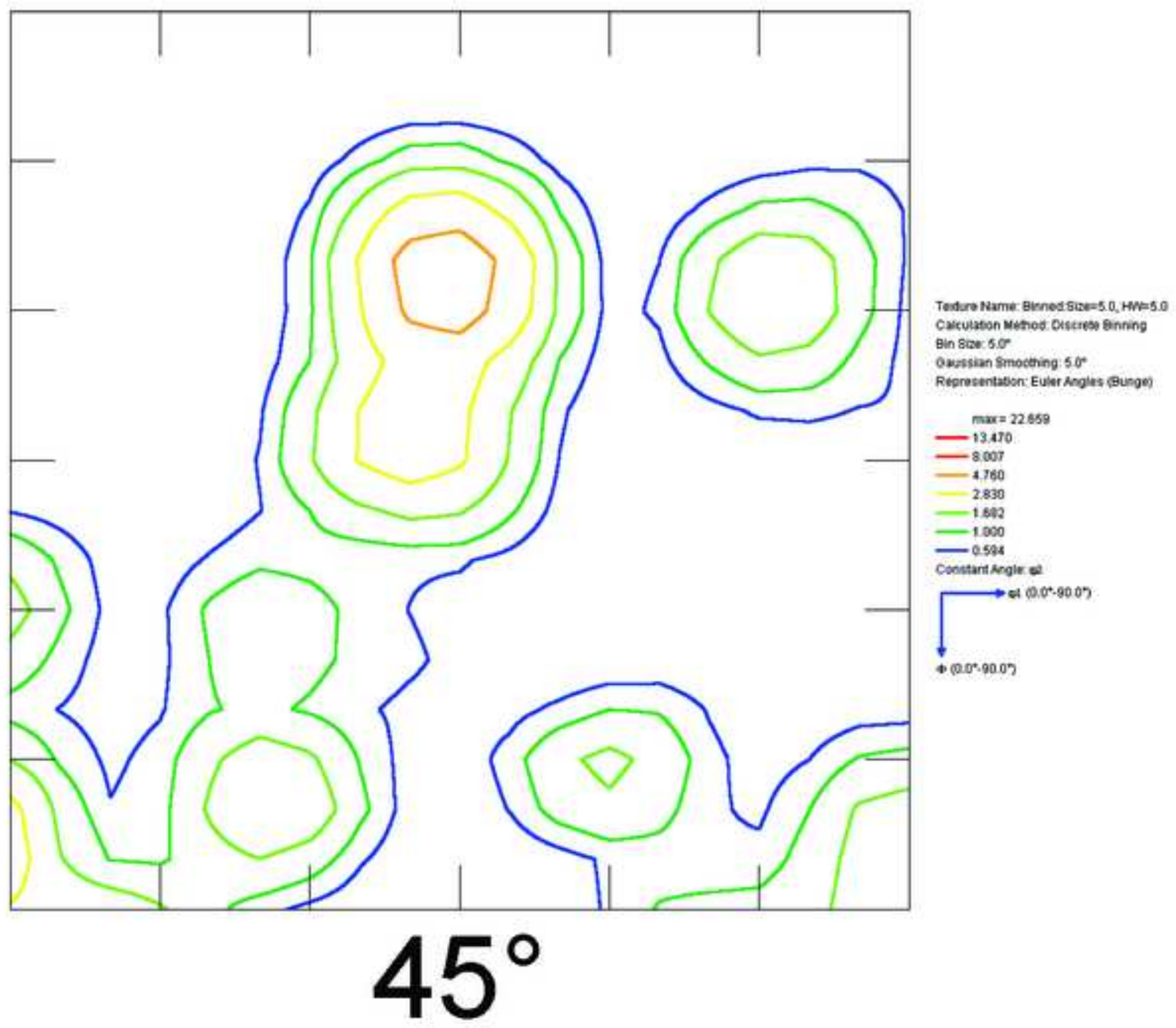


Click here to download high resolution image

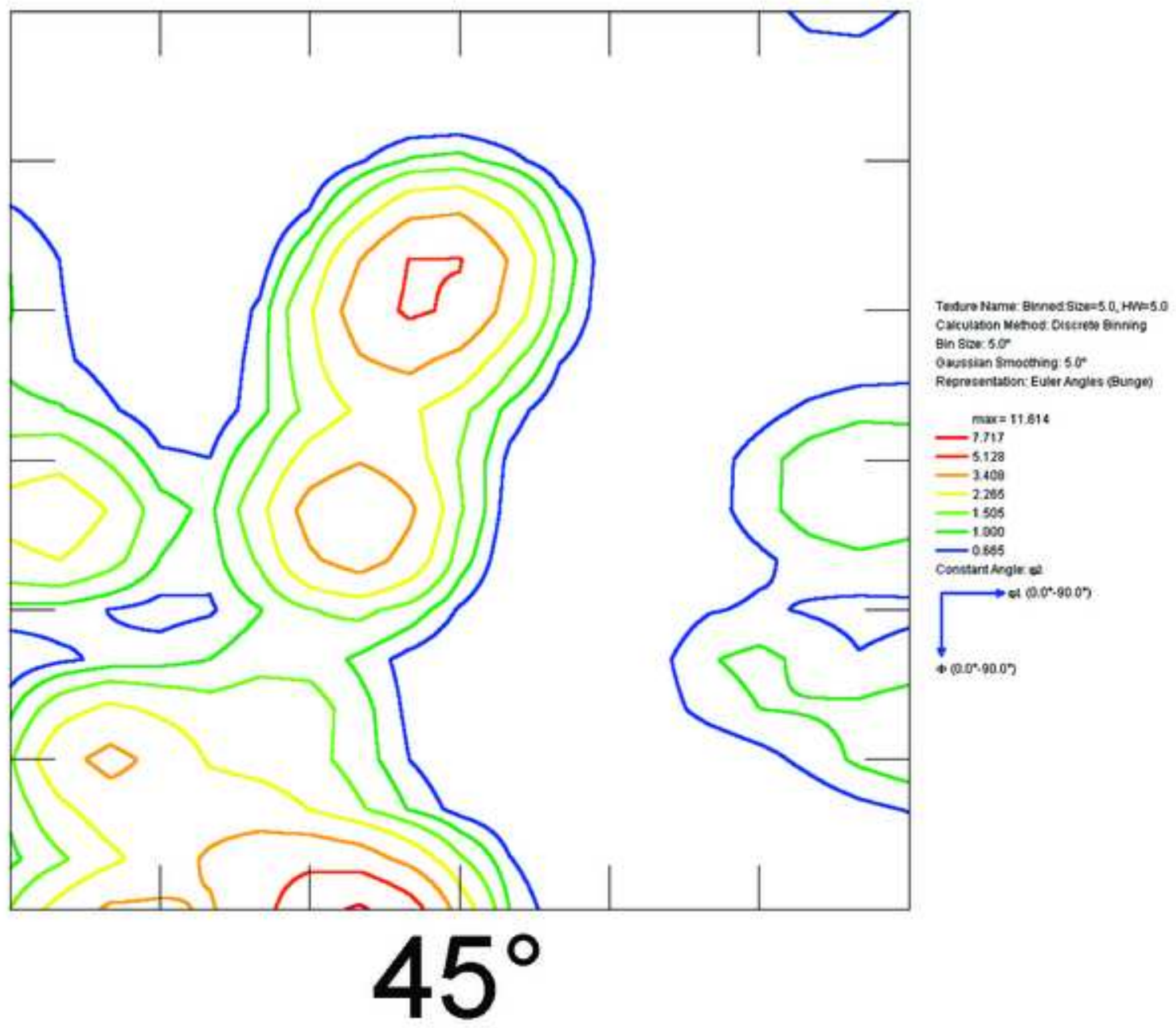


Click here to download high resolution image

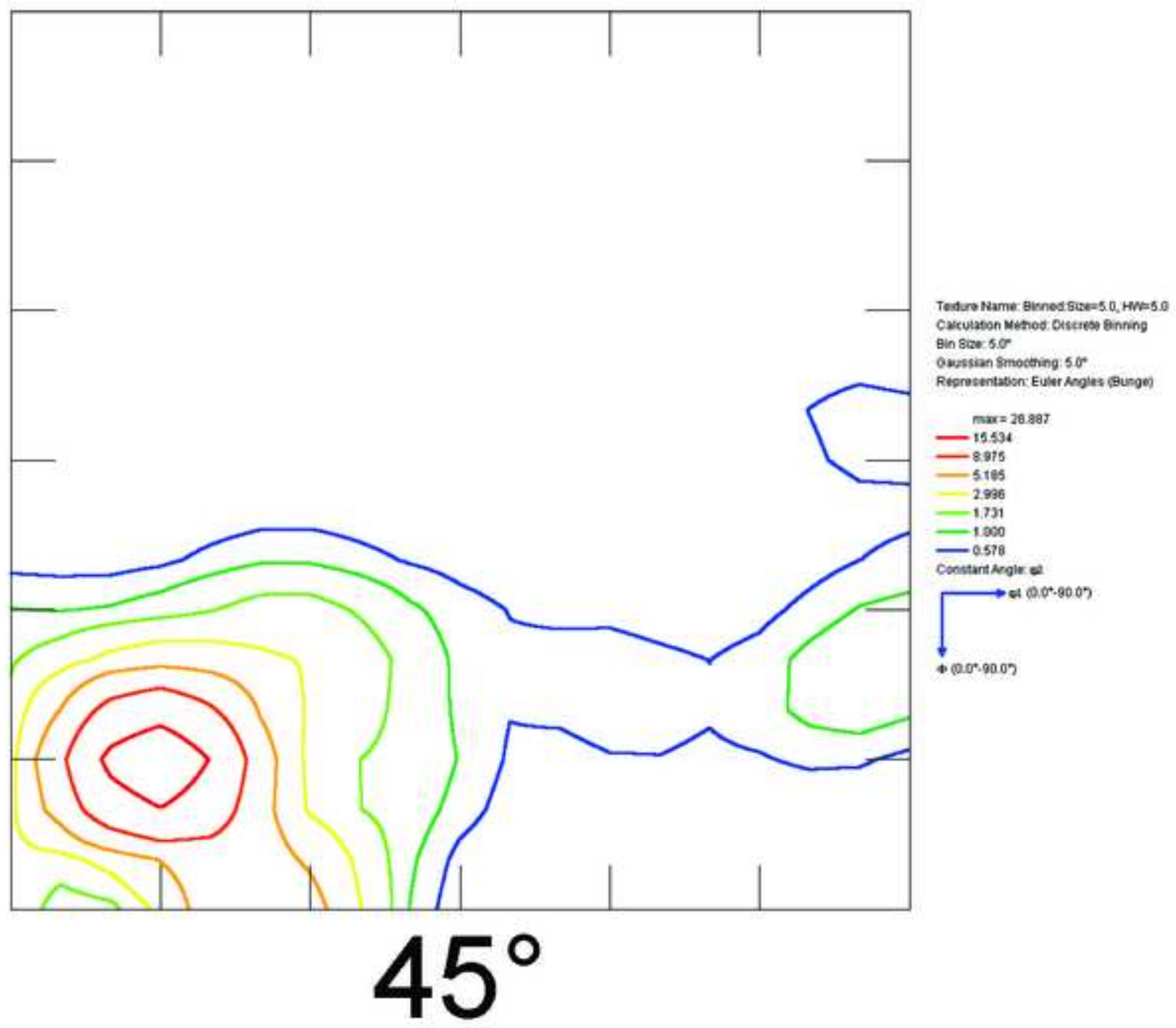




\section{gur}

Click here to download high resolution image

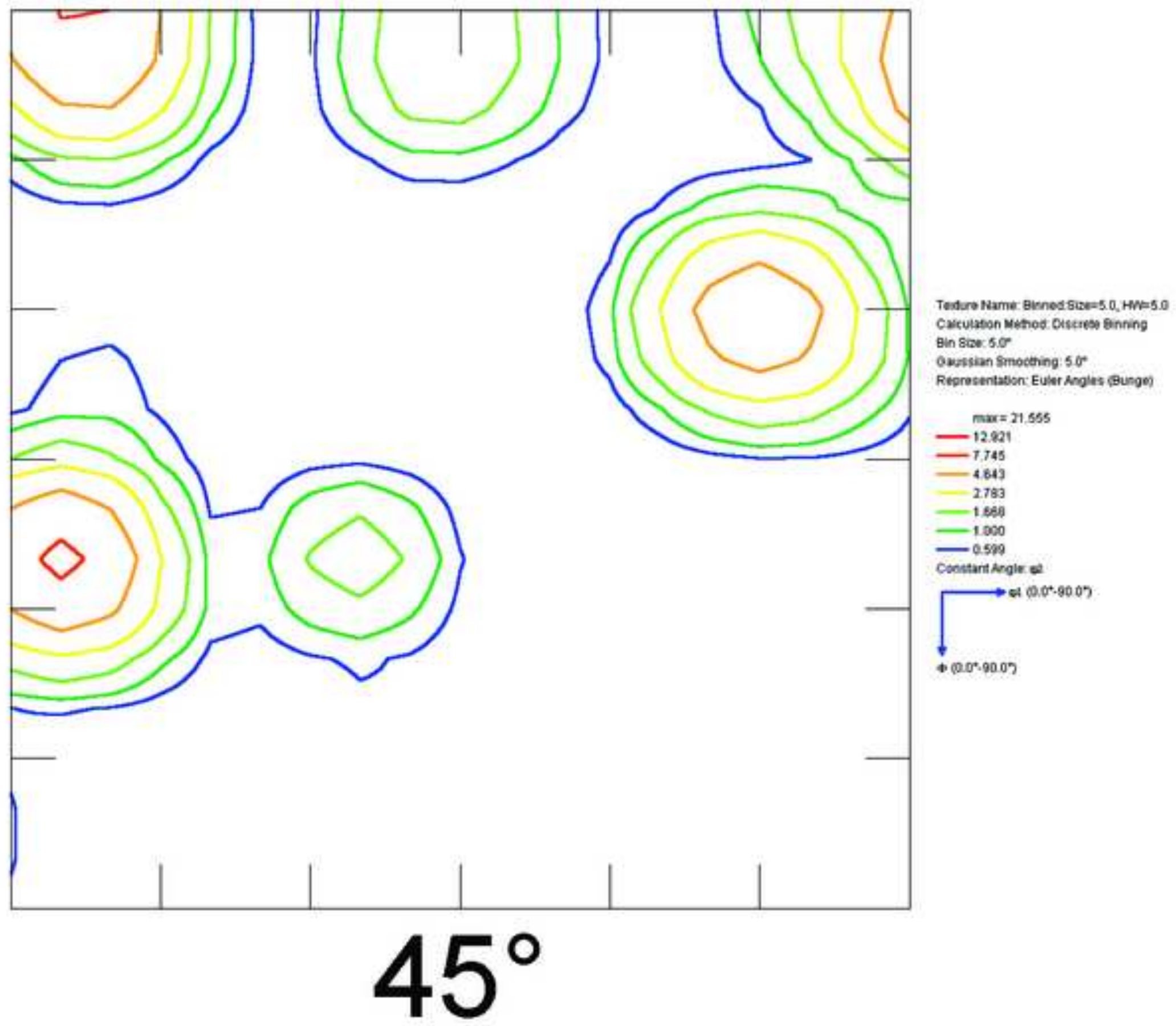




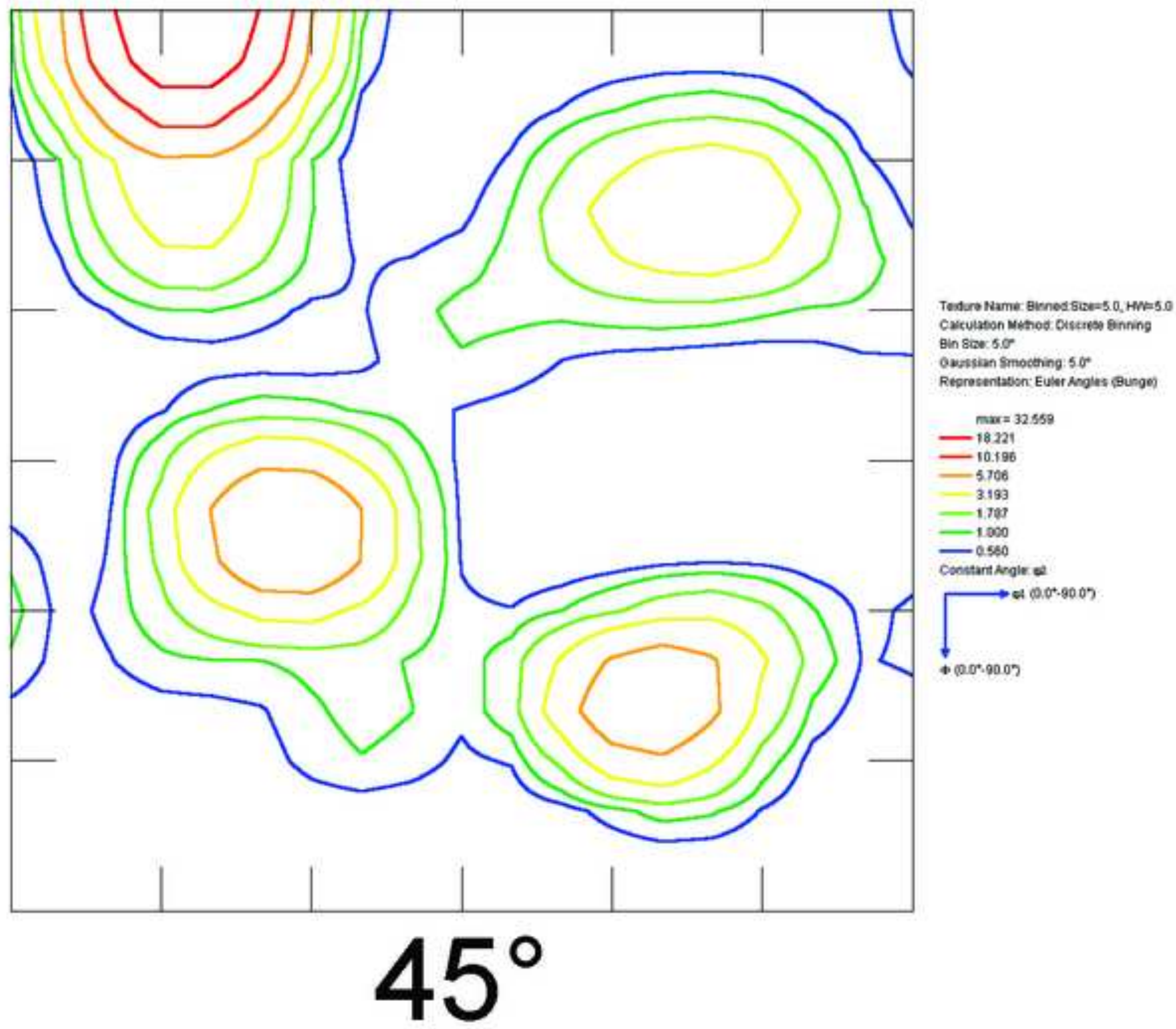


Table 1. Chemical composition of the samples (wt\%).

\begin{tabular}{|c|c|c|c|c|c|c|c|c|c|}
\hline Sample ID & $\mathbf{S i}$ & $\mathbf{C}$ & $\mathbf{M n}$ & $\mathbf{N}$ & $\mathbf{C r}$ & $\mathbf{N i}$ & $\mathbf{A l}$ & $\mathbf{P}$ & $\mathbf{F e}$ \\
\hline S05 & 0.48 & 0.005 & 0.066 & 0.0051 & 0.022 & 0.019 & 0.002 & 0.005 & Balance \\
\hline S10 & 1.00 & 0.008 & 0.036 & 0.0183 & 0.011 & 0.008 & 0.002 & 0.007 & Balance \\
\hline S15 & 1.52 & 0.003 & 0.042 & 0.0022 & 0.014 & 0.012 & 0.002 & 0.005 & Balance \\
\hline S20 & 2.03 & 0.006 & 0.037 & $<0.001$ & 0.015 & 0.017 & 0.003 & 0.001 & Balance \\
\hline S25 & 2.55 & 0.006 & 0.036 & $<0.001$ & 0.015 & 0.017 & 0.003 & 0.002 & Balance \\
\hline S30 & 2.99 & 0.006 & 0.036 & $<0.001$ & 0.014 & 0.016 & 0.003 & 0.002 & Balance \\
\hline
\end{tabular}


Table 2. Texture components intensities of the samples after the first rolling program.

\begin{tabular}{|l|r|r|r|r|r|}
\cline { 2 - 6 } \multicolumn{1}{c|}{} & \multicolumn{5}{c|}{ First rolling program } \\
\cline { 2 - 6 } \multicolumn{1}{c|}{} & (001)[0-10] & (001)[1-10] & (110)[001] & (110)[1-10] & $<111>/ /$ ND components \\
\hline S05 & 1.407 & 0 & 0 & 1.407 & 1.407 \\
\hline S10 & 0.553 & 0 & 0 & 1.807 & 1 \\
\hline S15 & 2.35 & 1 & 0 & 0 & 2.35 \\
\hline S20 & 0 & 0 & 1.659 & 0 & 7.578 \\
\hline S25 & 0 & 0 & 0 & 0.478 & 0 \\
\hline S30 & 0 & 0 & 0 & 1.636 & 0 \\
\hline
\end{tabular}


Table 3. Texture components intensities of the samples after the second rolling program.

\begin{tabular}{|l|r|r|r|r|r|}
\cline { 2 - 6 } \multicolumn{1}{c|}{} & \multicolumn{5}{c|}{ Second rolling program } \\
\cline { 2 - 6 } \multicolumn{1}{c|}{} & \multicolumn{6}{c|}{ (001)[0-10] } & (001)[1-10] & (110)[001] & (110)[1-10] & $<111>/ /$ ND components \\
\hline S05 & 0 & 0 & 0.642 & 1.557 & 2.425 \\
\hline S10 & 0 & 2.83 & 1.682 & 0 & 1 \\
\hline S15 & 0 & 0 & 0 & 1.505 & 3.408 \\
\hline S20 & 0 & 0 & 0 & 1.731 & 0 \\
\hline S25 & 1.668 & 4.643 & 0 & 0 & 7.745 \\
\hline S30 & 0 & 3.193 & 0 & 0 & 5.706 \\
\hline
\end{tabular}


Table 4. Texture components intensities at the surface and center of the samples after the second rolling program.

\begin{tabular}{|l|r|r|r|r|r|}
\cline { 2 - 6 } \multicolumn{1}{c|}{} & \multicolumn{6}{c|}{ Rolling surface } \\
\cline { 2 - 6 } \multicolumn{1}{c|}{} & (001)[0-10] & (001)[1-10] & (110)[001] & (110)[1-10] & $<111>/ /$ ND components \\
\hline S05 & 0 & 0 & 0.703 & 1.423 & 2.88 \\
\hline S10 & 1.694 & 0 & 1 & 2.869 & 1.694 \\
\hline S15 & 0 & 0.631 & 0 & 1 & 3.981 \\
\hline S20 & 2.034 & 1 & 1 & 0 & 2.034 \\
\hline S25 & 3.442 & 3.442 & 0 & 2.28 & 7.847 \\
\hline S30 & 3.257 & 0.554 & 0 & 1.805 & 3.257 \\
\hline & & & & Center & \\
\cline { 2 - 6 } & (001)[0-10] & $(001)[1-10]$ & $(110)[001]$ & $(110)[1-10]$ & $<111>/ /$ ND components \\
\hline S05 & 0 & 0 & 0 & 1.461 & 1 \\
\hline S10 & 0 & 0.558 & 1.792 & 0 & 0.613 \\
\hline S15 & 0 & 0 & 0.613 & 0 & 1.793 \\
\hline S20 & 0.558 & 0 & 0 & 0 & 1.685 \\
\hline S25 & 0 & 2.84 & 0 & 0 & 0.488 \\
\hline S30 & 1 & 2.05 & 0 & 0 & 1 \\
\hline
\end{tabular}

